persuade their local budget holder to support referral to Henderson, many additional comments indicate feelings of impotence in achieving this aim.

The pessimism reported in an earlier study regarding psychiatrists' attitudes towards prognosis for personality disorders (Lewis \& Appleby, 1988) was not found in our survey. Three-quarters of referrers who responded to the question felt that admission to Henderson had helped their client with their problems. Perhaps this difference is because our survey dealt only with those professionals who had actually seen and referred a PD client for treatment rather than the hypothetical client in the Lewis \& Appleby survey. Although many short term 'crisis responses' are ineffective as therapeutic interventions, the long term efficacy of in-patient psychotherapy or a therapeutic community approach in managing personality disorders has been demonstrated (Kernberg, 1982; Vaglum et al, 1990; Dolan et al, 1990). In contrast to the 'crisis response' approach, which is demanding of professionals time and effort and is difficult to cost accurately, such interventions may initially seem more expensive, but if effective are cheaper in the longer term.

It seems that for our referrers the pessimism surrounding personality disordered clients is not actually related to their 'treatability' per se but more worryingly it is linked to the feelings that post the NHS Bill such clients will be 'bottom of the pile' in terms of funding. Perhaps "the patients psychiatrists dislike" will fast become "the patients budget managers dislike" as well.

\section{References}

Dolan, B. M. \& Norton, K. (1990) Is there a need to safeguard specialist psychiatric units in the NHS? Henderson Hospital: a case in point. Psychiatric Bulletin, $14,72-76$

, Wilson, J. \& Evans, C. D. H. (1990) Therapeutic community treatment for personality disordered adults: a long term follow up study paper presented at British Psychology Society London Conference.

KERNBERG, O. (1982) Advantages and liabilities of the therapeutic community. In The Individual and the Group (ed. M. Pines). New York: Plenum Press.

LEWIS, G. \& APPLEBY, L. (1988) Personality disorders: the patients psychiatrists dislike. British Journal of Psychiatry, 153, 44-49.

VAglum, P. et al (1990) Treatment response of severe and non-severe personality disorders in a therapeutic community day unit. Journal of Personality Disorders, 4 , 161-172.

\title{
The physical health of old long stay in-patients in one psychiatric hospital
}

\author{
Mary Stewart, Senior Registrar, Andrew Duncan Clinic, Royal Edinburgh Hospital, \\ Edinburgh EH10 5HF
}

The provision of care for patients with chronic mental illness is changing with the gradual closure of mental hospitals and the expectation that this group will be largely cared for in the community. In Scotland the process is only beginning. A recent Scottish survey examined the demographic, social and clinical characteristics of 2605 "old long-stay" in-patients, defined as those in hospital more than six years and under 65 years of age at the time of last admission (McCreadie et al, 1991). Patients in 18 psychiatric hospitals serving $83 \%$ of the Scottish population were studied. Results showed the population was elderly, $70 \%$ being over 60 years of age, and nearly $40 \%$ over 70 years. The aim of the present study was to look at the physical health of the old long-stay population in one hospital, namely Crichton Royal, Dumfries, because of the implications of physical health care needs for the management of this group in the community.

\section{The study}

The survey recorded the age, sex and diagnosis (ICD9, World Health Organization, 1978) of the 168 old long-stay patients from Crichton Royal Hospital, Dumfries who were survivors of McCreadie's study (1991), the present one being carried out five months later. By interviewing senior nurses who had known 
the patients at least six months, measures of mobility, hearing, eyesight and incontinence were obtained (Appendix). Medication dispensed over the previous month was recorded and classified according to the British National Formulary. Currently active medical problems were identified by review of medical casenotes and medication kardex as well as discussion with nursing staff. A problem was present if reported in the past month.

\section{Findings}

The 168 old long-stay in-patients comprised $52 \%$ males with $80 \%$ aged over 60 years (range $34-100$ ). Fifty-six per cent were schizophrenic (ICD 295, 297), $27 \%$ mentally handicapped (ICD 317-319), 8\% had organic brain disease (ICD 290-291, 310, 345 and 094), $6 \%$ manic depressive illness (ICD 296) and 3\% other diagnoses. Thirty-one patients $(19 \%)$ had had one leucotomy and $7(4 \%)$ two leucotomies.

\section{General health problems}

Twenty-four per cent were unable to walk unaided. Seventeen per cent had significant hearing impairment. Eight per cent were either partially or totally blind. Incontinence of urine at least once per week was reported in $27 \%$ by day and $30 \%$ by night. Twenty-four per cent had both episodes of faecal incontinence or soiling and urinary incontinence. In $9 \%$ of the total population this occurred at least once weekly and in $4 \%$ on a daily basis. Only half the sample population (49\%) was reported free of incontinence problems. Those with organic brain disease had the greatest prevalence of incontinence problems, $64 \%$ of this group having episodes of double incontinence.

\section{Medication}

Medication received (as a percentage of all patients) was as follows:

(a) Regular psychotropic medication: total on antipsychotics $58 \%$ (oral only, $31 \%$; IM only, $15 \%$; oral and IM, $12 \%$ ), antiparkinsonians $28 \%$ ( $48 \%$ of these on neuroleptics), anticonvulsants $16 \%$, antidepressants $14 \%$, hypnotics/anxiolytics $7 \%$, lithium $7 \%$ and others $3 \%$.

(b) Regular non-psychotropic medication: laxatives $34 \%$, diuretics $12 \%$, vitamins/dietary supplements $12 \%$, endocrine $8 \%$, skin preparations $8 \%$, other CVS drugs $8 \%$, regular analgesics $6 \%$, antibiotics (current) $5 \%$, ENT/eye preparations $5 \%$, respiratory system drugs $4 \%$, GIS drugs other than laxatives $4 \%$, and others $3 \%$.

In summary, $13 \%$ were receiving no medication, $57 \%$ were receiving regular non-psychotropic medication (although $20 \%$ were on laxatives or skin preparations only) and $73 \%$ received regular psychotropic medication.

\section{Physical illness}

Neurological disorders were the most prevalent (32\%). They included epilepsy ( $9 \%$ of all patients), tardive dyskinesia (TD) (6\%), idiopathic Parkinson's disease (3\%), drug-induced Parkinsonism (3\%) and Huntington'schorea (1\%). A further 13 patients( $8 \%$ ) had a past history of epilepsy but had had no seizures or anticonvulsant treatment in the past two years. Other diagnoses were cardiovascular problems present in $25 \%$ of patients (for example, congestive heart failure $11 \%$, hypertension $5 \%$ ), gastrointestinal in $14 \%$ (particularly severe constipation requiring regular enemas in $5 \%$ ) and endocrine in $11 \%$ (mainly hypothyroidism $5 \%$ and diabetes mellitus $3 \%$ ). In the $10 \%$ with genito-urinary problems about half were due to prostatism and/or retention. Nine per cent of diagnoses were in the respiratory system and of the $8 \%$ with other diagnoses half were anaemic. Seven patients $(4 \%)$ had received treatment for a tumour in the past year or had a known inoperable growth. Only $20 \%$ of the population were apparently free of significant ill-health.

\section{Comment}

The Crichton Royal Hospital old long-stay patients are broadly equivalent to populations in other Scottish psychiatric hospitals. The population does, however, differ in having more mentally handicapped patients $(27 \%$ compared with the overall Scottish figure of $10 \%$ ) and secondly, a large number of patients $(\mathrm{N}=77,45 \%)$ originally admitted from outside the present catchment area.

This study emphasises that old long-stay patients are an elderly population and often physically disabled, with mobility problems and incontinence in particular. A significant minority had physical illness, most notably in the neurological and cardiovascular systems. This level of morbidity means that patients require supervision and nursing care additional to that needed for psychiatric illness and rehabilitation. It might also make community placement difficult as has been pointed out by Abbott et al (1988) who found $26 \%$ with physical handicap (mainly blindness, deafness and immobility) in a long-stay psychiatric population. The authors also reported high rates of serious physical illness $(27 \%)$, mainly ischaemic heart disease and malignancy.

The general physical health of long-stay psychiatric populations has not been extensively investigated. In the United Kingdom a small number of studies have included investigation of specific physical problems. For example, Owens \& Johnstone 
(1980) examined the neurological status of 510 long-stay schizophrenics, and found $78 \%$ had some neurological abnormality, $72 \%$ having a disorder of movement or tone. A previous study of all known schizophrenics in an area served by Crichton Royal Hospital found the prevalence of both TD and Parkinsonism to be $31 \%$. As over half the old longstay population in the present study were schizophrenic and $58 \%$ were receiving antipsychotic medication, the figures of $10 \%$ for TD and $10 \%$ for Parkinsonism (idiopathic and iatrogenic) recorded in the casenotes of those on antipsychotic medication suggest that often movement disorder is going unrecorded. It is difficult to compare the mobility and incontinence problems of the Crichton Royal population with studies of elderly people in the community because of demographic and methodological difficultics. However, by way of a general indication of incontinence problems in the community, Campbell et al (1985) found $12 \%$ of those aged 65 or over, and $22 \%$ of the over 80 s in a New Zealand population were incontinent of urine. In the present study $80 \%$ of the population were over 60 years of age and half were reported to have incontinence problems. This would represent a considerable workload for nursing staff or caregivers in the community.

The present survey found only $20 \%$ of patients apparently free of ill-health. As this is a chart-based survey of physical health, the findings can be considered an underestimate of illness. At present, Scottish long-stay patients are largely hospital based with physical health care being provided mainly by nursing and junior medical staff of psychiatric hospitals. If such patients are to be discharged into the community questions will arise about how much physical care they are going to require, and who will provide it. From a medical point of view the changes in GP contracts do not make this an attractive population to be added to practice lists. Nor would it be appropriate for psychiatrists to take on this task with a scattered population. Honig et al (1989) discussed the physical health of a younger, less psychiatrically impaired population of chronic patients based in the community in the Netherlands. He felt that an ambulatory psychiatric service could not take on the responsibility of monitoring the physical health of chronic psychiatric patients. This is even more the case when it comes to older chronic patients.

Those planning community care for the old longstay population should not overlook the need for treatment of physical illness, much of which is chronic in nature. In some cases patients may now be too physically disabled to leave hospital. It must be remembered that lack of motivation is often an integral part of chronic mental disorder and may deter patients from seeking help when they become physically unwell. I would suggest that physical care of this group needs to be carefully planned, both from a medical and nursing point of view. This must include regular review of individual patients and monitoring the effect of community placement on levels of morbidity, rather than an expectation of seeing a doctor only when there is obvious illness.

\section{Acknowledgements}

I am grateful to Dr R. McCreadie for his help and encouragement, nursing staff at Crichton Royal Hospital, Dumfries for their co-operation, and Drs J. Dyer and I. Pullen for useful comments.

\section{References}

Abbott, P. M., Cookson, I. B., Bentley, J. \& Sillince, C. (1988). Psychiatric morbidity of long-stay hospital population (letter). British Medical Journal, 297, 1334.

Campbell, A. J., Reinken, J. \& McCosh, L. (1985). Incontinence in the elderly: prevalence and diagnosis. Age and Ageing, 14, 65-70.

Honig, A., Pop, P., Tan, E. S., Philipsen, H. \& Romme, M. A. J. (1989). Physical illness in chronic psychiatric patients, from a community psychiatric unit. British Journal of Psychiatry, 155, 58-64.

McCreadie, R. G., Stewart, M., Robertson, L. \& Dingwall, J. M. (1991). The Scottish survey of old long-stay in-patients. British Journal of Psychiatry, 158, 398-402.

OWENS, D. G. \& JOHNSTONE, E. C. (1980). The disabilities of chronic schizophrenia - their nature and the factors contributing to their development. British Journal of Psychiatry, 136, 384-395.

\section{Appendix}

Physical Health Scales

(1) Mobility

(i) bedfast, (ii) uses wheelchair, (iii) walks aided, (iv) walks unaided.

(2) Hearing and eyesight Items from CAPE Scale. Pattie, A. M. and Gilleard C. J. (1979) Clifton Assessment Procedures for the Elderly. Behaviour Rating Scale. Hodder \& Stoughton, Sevenoaks, Kent.

(3) Incontinence Urinary in daytime, urinary at night and faecal incontinence or soiling, each recorded according to frequency in 6 categories from none to daily. 